\title{
Morfoanatomia do sistema subterrâneo de Smilax subsessiliflora (Smilacaceae) ${ }^{1}$ \\ Morphoanatomy of the underground system of Smilax subsessiliflora (Smilacaceae)
}

\author{
Alessandra Ribeiro Guimarães ${ }^{2}$, Cecilia Gonçalves Costa $^{3,5} \&$ \\ Regina Helena Potsch Andreata ${ }^{4,5}$
}

\begin{abstract}
Resumo
Smilax subsessiliflora Duhamel, espécie exclusivamente brasileira, tem por habitat a floresta Atlântica, mesófila e as matas de restinga. Este trabalho tem por objetivo descrever a morfoanatomia do sistema subterrâneo de $S$. subsessiliflora. O sistema subterrâneo da espécie em questão é constituído pelo rizóforo, do qual partem os ramos caulinares e as raízes adventícias. O rizóforo apresenta epiderme uniestratificada com estômatos, córtex com células de paredes espessadas e lignificadas, meristema de espessamento primário e cilindro vascular, integrado por feixes colaterais. Das raízes adventícias que partem do rizóforo originam-se outras que se distinguem pelo calibre e pela cor. Aquelas apresentam córtex externo, constituído por células parenquimáticas e córtex interno, constituído por esclereídes, que passam a exercer a função de revestimento, após a eliminação do córtex externo. O cilindro vascular é poliarco e sifonostélico. Grãos de amido ocorrem no periciclo e na medula. No córtex das raízes laterais detectaram-se endomicorrizas arbusculares. As características anatômicas observadas no sistema subterrâneo de $S$. subsessiliflora se assemelham às relatadas para o rizóforo de $S$. quinquenervia.

Palavras Chaves: caule, monocotiledôneas, raiz, rizóforo, Smilacaceae.

Abstract

Smilax subsessiliflora Duhamel, a native Brazilian species, inhabits the Atlantic rain forest, Mesophytic forest and Restinga forest. This study aims to describe the morphoanatomy of the underground system of S. subsessiliflora and compare the results to literature data. The underground system of the analyzed species is composed of the rhizophore, which emits the shoots and adventitious roots. The rhizophore has unistratified epidermis with stomata, cortex with thick lignified cell walls, primary thickening meristem (MEP) and vascular cylinder composed of collateral bundles. In the adventitious roots emitted by the rhizophore, other roots are formed, distinguished by thickness and color. These have external cortex composed by parenchyma and inner cortex (composed of sclereids) that becomes the outermost part after the elimination of the external cortex. The vascular cylinder is polyarch and siphonostelic. Starch grains are present in pericycle and pith. Arbuscular mycorrhizae were detected in the cortex of the lateral roots. The anatomical characters observed in the underground system of S. subsessiliflora are similar to those of the rhizophore of S. quinquenervia.
\end{abstract}

Key words: stem, monocotyledons, root, rhizophore, Smilacaceae.

\section{Introdução}

Smilacaceae, situada na ordem Liliales, tem distribuição predominantemente tropical e subtropical, com menor representatividade nas regiões temperadas (Andreata 2009).
Smilax é constituído por cerca de 300 espécies das quais 32 ocorrem no Brasil e são conhecidas popularmente como "salsaparilha" ou "japecanga" (Andreata 1997; 2009). Dentre estas, 15 são exclusivamente brasileiras, e sua distribuição varia de

\footnotetext{
' Parte da dissertação de Mestrado da primeira autora, bolsista CAPES.

${ }^{2}$ Universidade Federal do Rio de Janeiro, Pós-Graduação - Botânica, Museu Nacional, Quinta da Boa Vista s/n, 20940-040, Rio de Janeiro, RJ, Brasil. alessandracastellan@gmail.com

${ }^{3}$ Instituto de Pesquisas Jardim Botânico do Rio de Janeiro, R. Pacheco Leão 915, 22460-030, Rio de Janeiro, RJ, Brasil.

${ }^{4}$ Instituto de Ciências Biológicas e Ambientais, Universidade Santa Úrsula, R. Fernando Ferrari, 75, 22231-040, Rio de Janeiro, RJ, Brasil.

${ }^{5}$ Bolsista de Produtividade CNPq
} 
restrita a ampla no território nacional, sendo mais comumente encontradas em formações florestais (Andreata 1997).

Na medicina popular há um extenso histórico com relação ao gênero Smilax (Peckolt 1936; Medeiros et al. 2007), sendo que várias espécies estão incorporadas em farmacopéias de diversos países. A Farmacopéia Brasileira (1929), embora com nomenclatura desatualizada, menciona quatro espécies indicadas empiricamente com base na coloração e no diâmetro da raiz (Martins \& Appezzato-da-Gloria 2006).

Muitos estudos têm sido desenvolvidos no campo da fitoquímica sobre espécies de Smilax dada a sua riqueza em compostos secundários (Silva 2006). Dentre eles, cita-se o trabalho de Hongzhu et al. (2004), onde são assinalados dois novos glucosídeos para o sistema subterrâneo de Smilax bockii Warb. Merecem também referência os trabalhos de Rugna et al. (2003; 2005). No primeiro, foi desenvolvido um estudo fitoquímico comparativo entre as folhas e o rizoma de Smilax campestris Griseb., e no segundo, os autores analisam os flavonóides ocorrentes em diferentes órgãos dessa planta.

Nos últimos anos houve um grande avanço científico em relação aos estudos químicos e farmacológicos de plantas medicinais, visando obter novos compostos com propriedades terapêuticas. Entretanto, o sucesso dessa linha de pesquisa depende da integração entre os conhecimentos botânico, químico e farmacológico. No âmbito da botânica, os estudos taxonômicos e anatômicos são de primordial importância dada a sua contribuição para a correta identificação das espécies medicinais, auxiliando desta forma, o controle de qualidade da matéria-prima utilizada nos fitoterápicos, o que proporciona maior confiabilidade ao usuário (Anvisa 2004).

Conforme reportado por Silva (2006), as partes utilizadas de Smilax para fins medicinais são as raízes e os rizomas, ou seja, o sistema subterrâneo.

O sistema subterrâneo das espécies de Smilax tem sido estudado por diferentes autores que divergem quanto à terminologia utilizada para designar a parte caulinar desse sistema. Cunha (1937), Oliveira et al. (1973), Guaglianone \& Gattuso (1991) e, recentemente, Palhares \& Silveira (2005) e Silva (2006) utilizaram o termo rizoma. Andreata \& Menezes (1999), fundamentadas nas características estruturais do órgão e em seu desenvolvimento, assim como em estudos anteriores sobre o gênero Vernonia Screb. (Menezes et al. 1979; Sajo \&
Menezes 1986; Rocha \& Menezes 1997), propuseram estender a designação de "rizóforo" ao órgão homólogo de Smilax quinquenervia Vell.

Esse termo foi indicado por Menezes et al. (1979), ao reinterpretarem o sistema subterrâneo de Vernonia psilophylla DC. e V. linearifolia Less. (Asteraceae). As autoras tomaram como base as observações de Goebel (1905 apud Menezes et al., 1979) "que relacionou o órgão espessado de Dioscorea com o órgão formador de raiz (rizóforo) em Selaginella, sem usar o termo rizóforo". Foi, entretanto, Ogura (1938) quem primeiro utilizou a palavra rizóforo para designar o órgão formador de raízes em Dioscorea (Menezes 2007).

Andreata \& Menezes (1999) observaram que em $S$. quinquenervia o rizóforo se desenvolve a partir das gemas cotiledonares, frisando que o órgão desempenha importante papel na ampliação da rizosfera, nas funções de armazenamento, condução de água e nutrientes e propagação vegetativa.

Tendo em vista as dúvidas que ainda persistem sobre a estrutura interna da porção caulinar do sistema subterrâneo das espécies de Smilax, propõe-se, neste trabalho, analisar a morfoanatomia desse sistema na espécie em $S$. subsessiliflora. Desta maneira, espera-se contribuir para ampliar os conhecimentos sobre os órgãos subterrâneos das espécies de Smilax, que são as partes utilizadas para fins medicinais.

\section{Material e Métodos}

Foram coletados três espécimes de Smilax subsessiliflora Duhamel em um fragmento de Mata Atlântica, numa propriedade particular localizada no município de Miguel Pereira, estado do Rio de Janeiro.

O material foi identificado pela Dra. Regina $\mathrm{H}$. Potsch Andreata e as exsicatas confeccionadas foram incorporadas ao Herbário RB: S. subsessiliflora, A.O. Dias Neto 47, 48, 51 (RB), com duplicatas nos herbários RUSU e R.

Para a análise anatômica foram coletados o rizóforo, em sua porção mediana, as raízes adventícias e suas laterais, nas regiões apical e subapical.

O material coletado foi fixado em FAA em etanol 50\%, segundo Johansen (1940) e preservado em etanol $70 \%$. O rizóforo foi incluído em polietilenoglicol (PEG) 1500 e seccionado em micrótomo de deslize, na espessura média de 20 $\mu \mathrm{m}$. Após clarificação com hipoclorito de sódio a $50 \%$, as secções foram lavadas em água destilada e coradas com safranina e azul de astra (Bukatsch 1972). As amostras das raízes foram incluídas em 
historesina, segundo Gerrits \& Smitd (1983), obtendose secções com 2-5 $\mu$ m de espessura ao micrótomo rotativo Jung, posteriormente coradas com azul de toluidina $0,05 \%$ em tampão fosfato de sódio $\mathrm{pH}$ 7,2 e ácido cítrico pH 4,5 (Sakai 1973).

Os testes histoquímicos foram realizados em material recém-coletado para detectar: substâncias pécticas, pelo vermelho de rutênio (Johansen 1940); amido, pelo lugol (Berlyn \& Miksche 1976); lignina, por meio da floroglucina em meio ácido (Johansen 1940) e por observação ao microscópio de fluorescência, usando a auramina (Considine \& Knox 1979). As substâncias lipídicas foram evidenciadas pelo Sudan black B e Sudan IV (Jensen 1962); a natureza dos cristais foi testada pelo ácido clorídrico e por observação ao microscópio de luz polarizada (MP) e os compostos fenólicos, detectados pela reação nitrosa, referida por Jensen (1962).

Para observação da epiderme do rizóforo foram utilizados fragmentos de aproximadamente $1 \mathrm{~cm}^{2}$, que foram submersos em solução de Jeffrey (Johansen 1940), e em seguida corados com safranina (Bukatsch 1972).

A morfologia do rizóforo foi documentada por meio de fotografias com câmera digital. Os detalhes anatômicos foram registrados com o auxílio de uma câmera digital Cool Snap Pro, acoplada ao microscópio óptico Olympus BX50, utilizando-se o software Image Pro Plus Versão 4.0 para Windows.

\section{Resultados}

\section{Morfologia externa}

O sistema subterrâneo de Smilax subsessiliflora é constituído pelo rizóforo e pelas raízes adventícias nele originadas. O rizóforo tem consistência lenhosa, coloração marrom, ramificação simpodial e é constituído de artículos cobertos por catafilos dispostos disticamente (Fig. 1a-b). Desta estrutura, conforme referido anteriormente, desenvolvem-se as raízes adventícias (Fig. 1a-c), de coloração marrom escuro, fibro-lenhosas na maturidade (Fig. 1b), que se estendem horizontalmente, atingindo vários metros de extensão. Quando jovens, são claras e de consistência macia.

\section{Morfologia interna \\ Rizóforo}

O rizóforo adulto apresenta epiderme uniestratificada com estômatos anomocíticos (Fig. 2a-b) e córtex formado por aproximadamente 25-30 estratos de células de parênquima (Fig. 2c), onde ocorrem esclereides (Fig. 3a), idioblastos fenólicos e ráfides de oxalato de cálcio. A camada mais interna do córtex é representada pela endoderme (Fig. 3a) e a seguir, observa-se o periciclo que se apresenta como uma larga faixa celular. A endoderme acompanha a saída das raízes adventícias e neste nível apresenta células de paredes lignificadas com espessamento em “O” (Fig. 3a).

A região do meristema de espessamento primário (MEP) é extensa, constituída por uma faixa contínua de 12-14 camadas celulares (Fig. 2c e 3b) que, no curso da diferenciação, têm suas paredes gradativamente espessadas e lignificadas (Fig. 4a). Esse aspecto foi confirmado pelo teste da floroglucina e por observação em microscopia de fluorescência.

No cilindro vascular atactostélico ocorrem feixes colaterais, visualizados nos sentidos transversal e longitudinal, e que se apresentam envoltos por bainha esclerenquimática (Fig. 2c, 3b e 4a). Alguns desses feixes vão constituir os traços vasculares dos ramos aéreos e/ou das raízes adventícias (Fig. 2c).

No rizóforo, mesmo sem tratamento prévio, são observados numerosos idioblastos fenólicos, assim como ráfides, gotas lipídicas e células contendo grãos de amido no cilindro vascular (Fig. 4b-c).

\section{Raiz}

No ápice de uma raiz adventícia observa-se, em secção longitudinal, a organização apical do tipo aberta (Fig. 5a, c). Nesta fase inicial de diferenciação, já ocorrem idioblastos fenólicos e de ráfides, nas regiões correspondentes ao córtex e à medula (Fig. 5a-b). A cerca de $3 \mathrm{~mm}$ do ápice radicular, tem início a zona pilífera. Os pêlos radiculares têm formato e dimensões variáveis, alguns com as paredes um tanto espessadas. Neste nível, as células da endoderme já apresentam todas as paredes espessadas, não sendo possível visualizar as estrias de Caspary.

Numa raiz mais desenvolvida, observa-se a epiderme uniestratificada com células alongadas no sentido anticlinal (Fig. 6a). O córtex é formado por células parenquimáticas, algumas das quais se apresentam colapsadas nas proximidades da periferia. Abundantes idioblastos fenólicos são vistos nessa região (Fig. 6a). As células parenquimáticas da porção mais interna do córtex diferenciaram-se, originando uma faixa esclerenquimática, integrada por cerca de quatro estratos de esclereides (Fig. 6a-b). Numa fase posterior de desenvolvimento a 


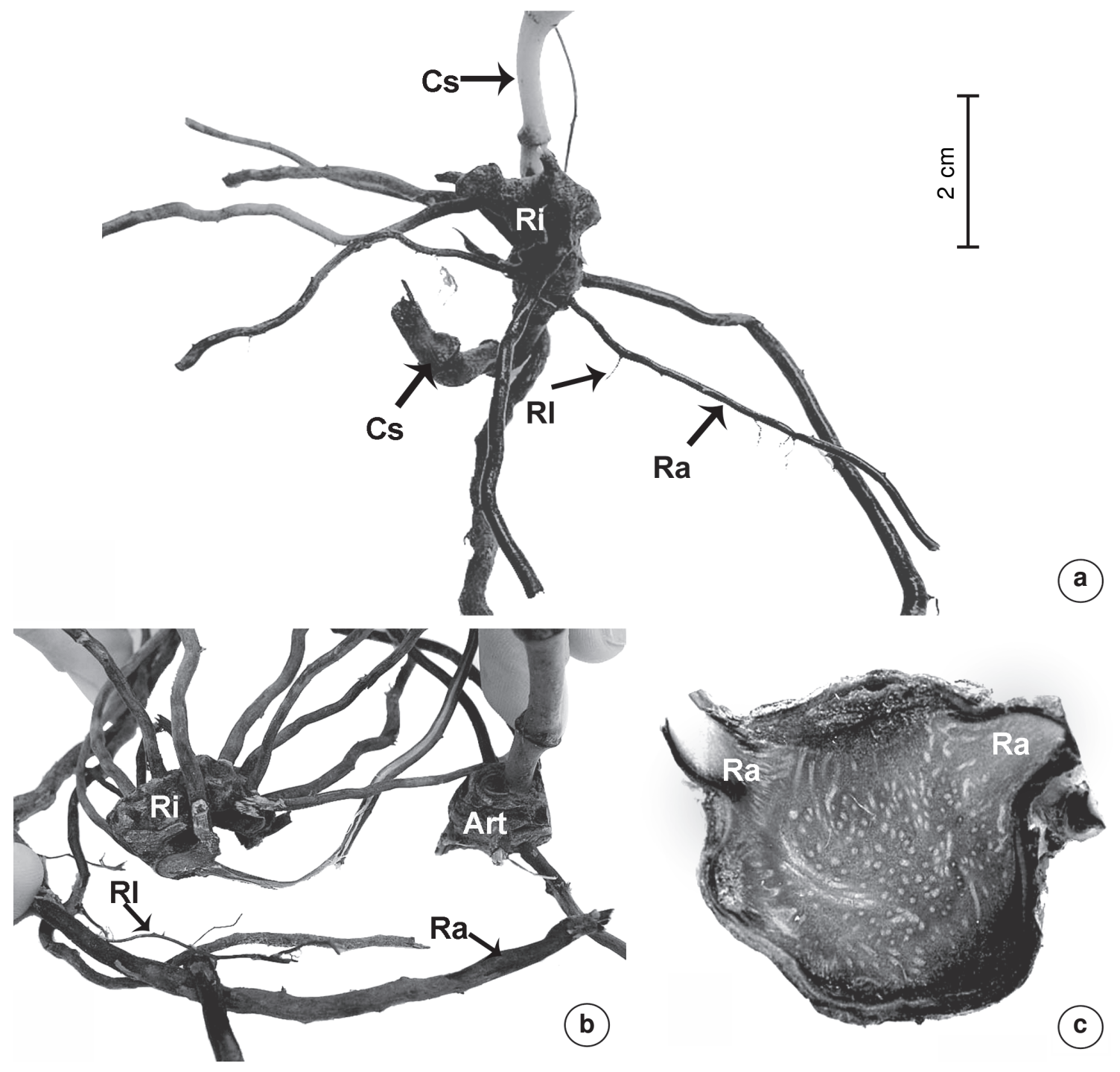

Figura 1 - Sistema subterrâneo de Smilax subsessiliflora - a. rizóforo, raízes adventícias e caule em sua porção subterrânea; b. detalhe do rizóforo e das raízes adventícias e laterais, e porção do rizóforo evidenciando um artículo; c. secção transversal do rizóforo, evidenciando a saída de raízes adventícias. $\mathrm{Cs}=$ caule porção subterrânea; $\mathrm{Ra}=$ raiz adventícia; $\mathrm{R} 1=$ raiz lateral; $\mathrm{Ri}=$ rizóforo; $\mathrm{Art}=$ artículo.

Figure 1 - Underground system of Smilax subsessiliflora -a. rhyzophore, adventitious roots and underground portion of stem; b. detail of the rhyzophore, adventitious and lateral roots, and a portion of the rhyzophore with an article; c. transverse section of the rhyzophore with the exit of adventitious roots. $\mathrm{Cs}=$ underground portion of stem; $\mathrm{Ra}=$ adventitious root; $\mathrm{Rl}=$ lateral root; $\mathrm{Ri}=$ rhyzophore; Art $=$ article.

epiderme e a porção externa do córtex são eliminadas e essas camadas passam a exercer a função de revestimento. Subjacente a essa faixa, visualiza-se a endoderme uniestratificada cujas células têm espessamento em "O" (Fig. 6 a-b).

O cilindro vascular é poliarco e sifonostélico. O periciclo é constituído por 3-4 camadas de células com paredes pouco espessadas (Fig. 6a), contendo grãos de amido. A medula é conspícua, formada por células parenquimáticas com abundante reserva amilífera (Fig. 6c). Nessa região observam-se ainda idioblastos fenólicos (Fig. 6c).

$\mathrm{Na}$ região pericíclica da raiz adventícia, originam-se as raízes laterais. Estas, por sua vez, dão origem a outras raízes laterais, ampliando a ramificação radicular. 

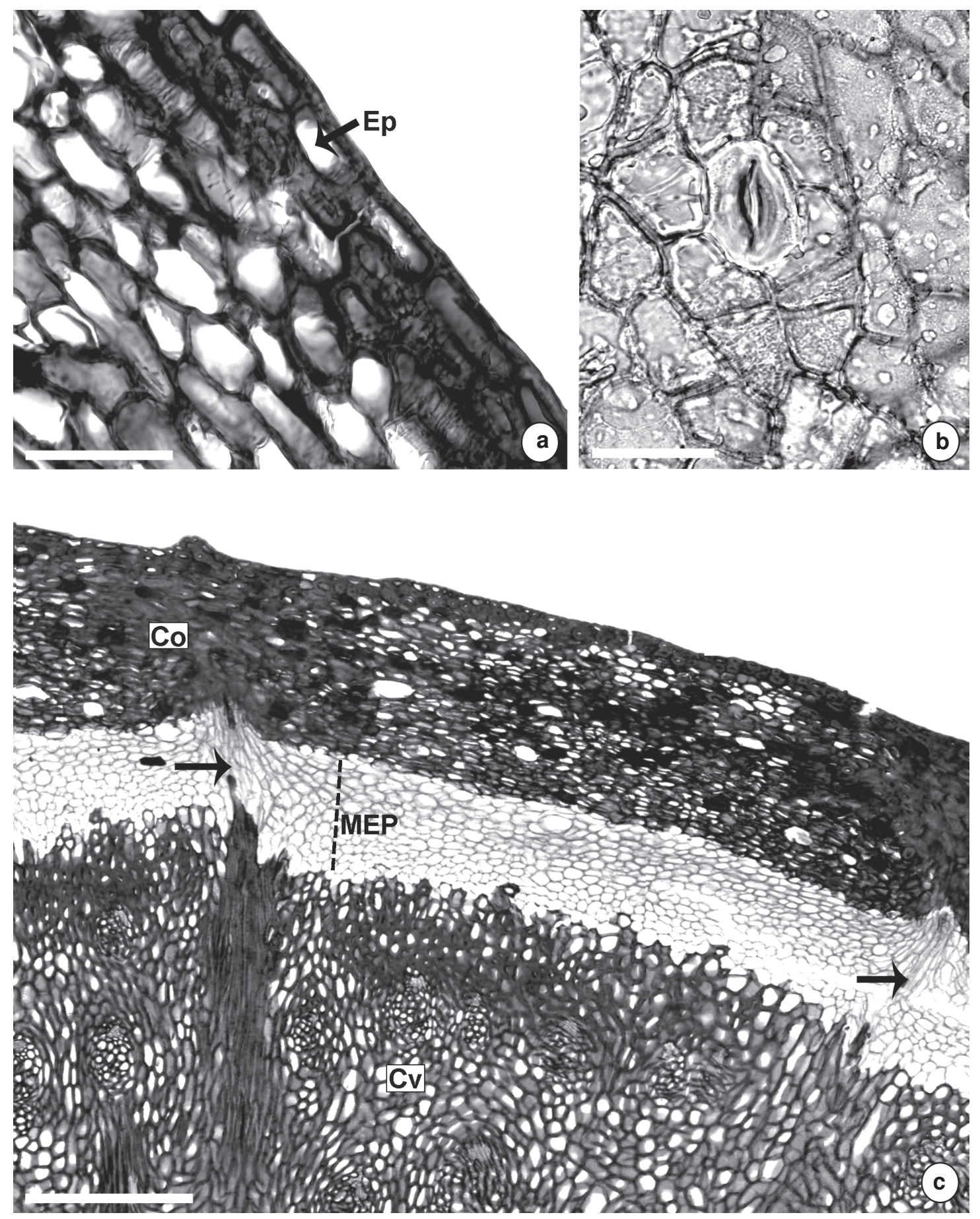

Figura 2 - Rizóforo de Smilax subsessiliflora. Secção transversal - a. epiderme uniestratificada; b. vista frontal da epiderme; estômato anomocítico; c. evidencia-se o córtex com células de paredes espessadas e lignificadas, além da região do meristema de espessamento primário (MEP) em várias camadas e traços vasculares (setas). Ep = epiderme; Co $=$ córtex $; \mathrm{MEP}=$ meristema de espessamento primário; $\mathrm{Cv}=$ cilindro vascular. Escalas: $10 \mu \mathrm{m}$ (a); $25 \mu \mathrm{m}$ (b); $50 \mu \mathrm{m}$ (c). Figure 2 - Rhyzophore of Smilax subsessiliflora. Transversal section - a. unistratified epidermis; $b$. frontal view of epidermis; anomocytic stomate; c. showing the cortex with thick and lignified walls, besides the primary thickening meristem (MEP) region in several layers and vascular traces (arrows). $\mathrm{Ep}=$ epidermis; $\mathrm{Cor}=$ cortex; $\mathrm{MEP}=$ primary thickening meristem; $\mathrm{Cv}=$ vascular cylinder. Scales: $10 \mu \mathrm{m}$ (a); $25 \mu \mathrm{m}$ (b); $50 \mu \mathrm{m}$ (c). 

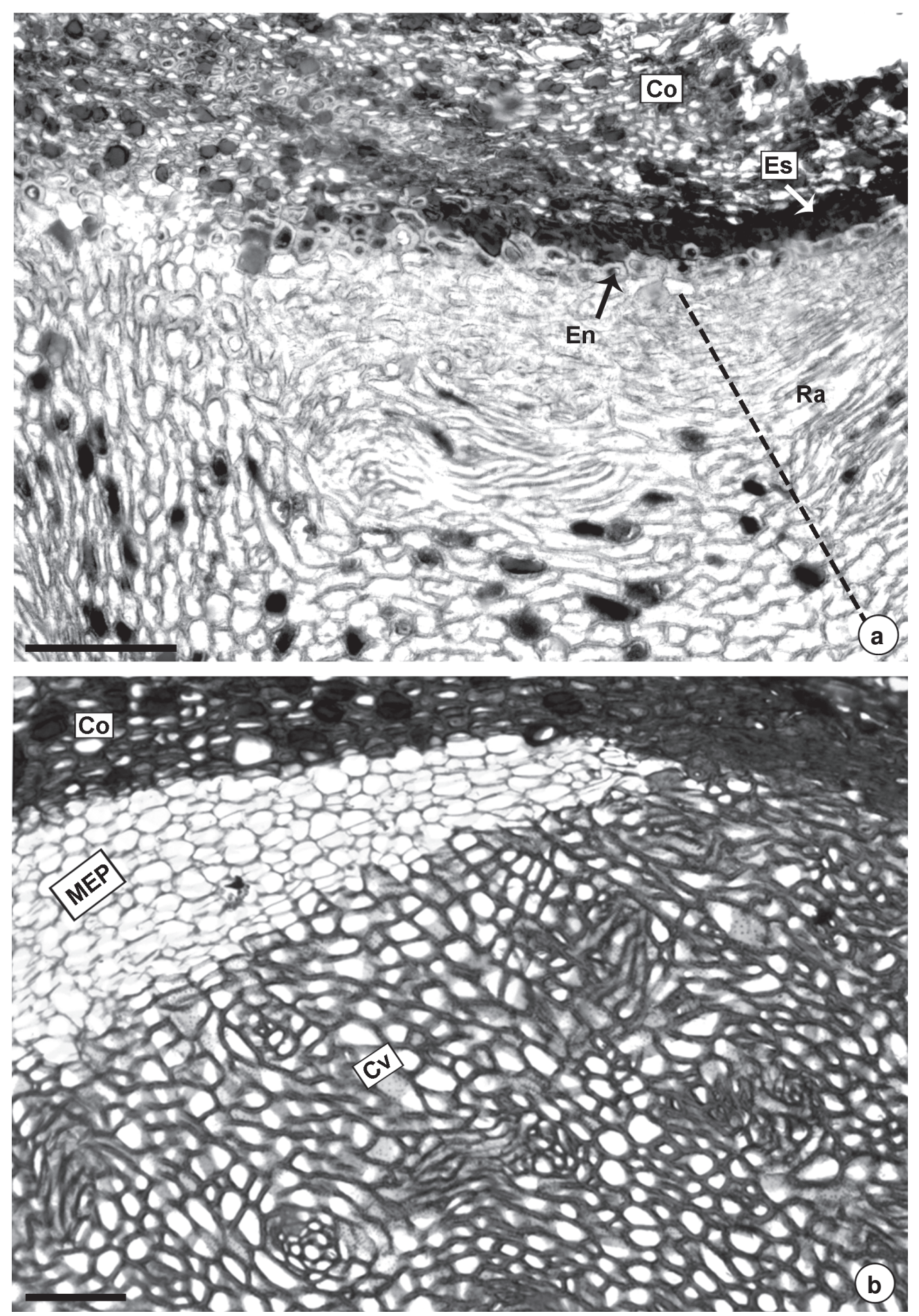

Figura 3 - Rizóforo de Smilax subsessiliflora. Secção transversal - a. observa-se saída de raiz adventícia e presença de córtex, com esclereides e endoderme; $b$. detalhe do rizóforo evidenciando a região do MEP. Algumas células em orientação radial. $\mathrm{Co}=$ córtex; Es = esclereides; $\mathrm{Cv}$ = cilindro vascular; $\mathrm{En}=$ endoderme; $\mathrm{Ra}=$ raiz adventícia; $\mathrm{MEP}$ $=$ meristema de espessamento primário. Escalas: $50 \mu \mathrm{m}(\mathrm{a}) ; 25 \mu \mathrm{m}(\mathrm{b})$.

Figure 3 - Rhyzophore of Smilax subsessiliflora. Transversal section - a. note the exit of adventitious root and cortex with sclereid band and endodermis; $b$. detail of the rhyzophore with MEP region. Some cells radially disposed. $\mathrm{Co}=$ cortex; Es $=$ sclereids; $\mathrm{Cv}=$ vascular cylinder; $\mathrm{En}=$ endodermis; $\mathrm{Ra}=$ adventitious root; $\mathrm{MEP}=$ primary thickening meristem. Scales: $50 \mu \mathrm{m}$ (a); $25 \mu \mathrm{m}$ (b). 


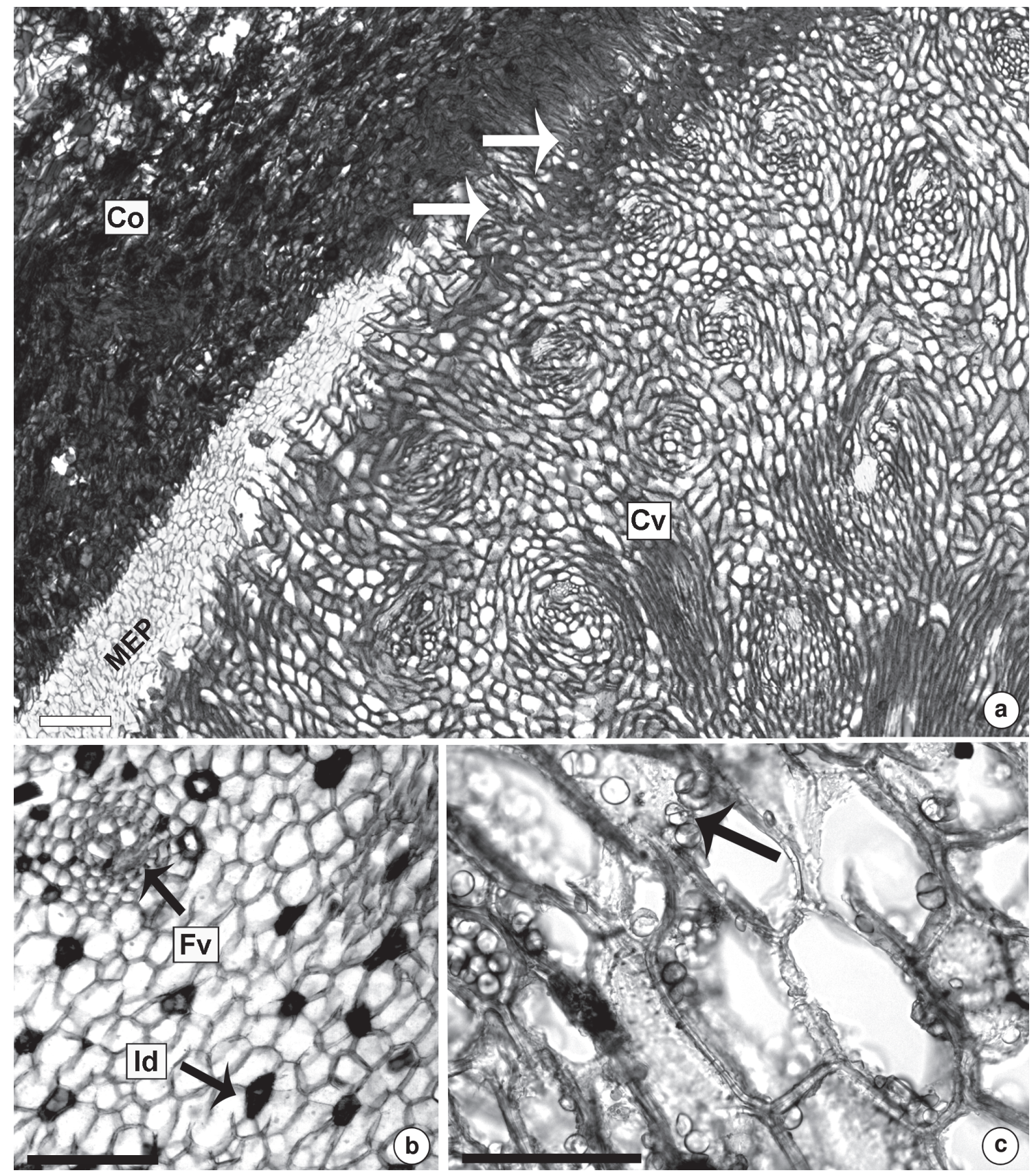

Figura 4 - Rizóforo de Smilax subsessiliflora. Secção transversal - a. região do MEP com células de paredes espessadas e lignificadas (setas); b. detalhe do cilindro vascular; notam-se idioblastos fenólicos e diminuto feixe vascular; c. detalhe do cilindro vascular evidenciando grãos de amido (seta) em células do parênquima. MEP = meristema de espessamento primário; $\mathrm{Id}=$ idioblastos fenólicos; $\mathrm{Co}=$ córtex; $\mathrm{Cv}=$ cilindro vascular; $\mathrm{Fv}=$ feixe vascular. Escalas: $25 \mu \mathrm{m}$ (a); $50 \mu \mathrm{m}$ (b-c).

Figure 4 - Rhizophore of Smilax subsessiliflora. Transversal section - a. MEP region with thick lignified walls (arrows); b. detail of the vascular cylinder; note phenolic idioblasts and small vascular bundle; c. detail of vascular cylinder with starch grains (arrow) in parenchyma cells. $\mathrm{MEP}=$ primary thickening meristem; $\mathrm{Id}=$ phenolic idioblasts; $\mathrm{Co}=$ cortex; $\mathrm{Cv}=$ vascular cylinder; $\mathrm{Fv}=$ vascular bundle. Scale: $25 \mu \mathrm{m}$ (a); $50 \mu \mathrm{m}$ (b-c). 


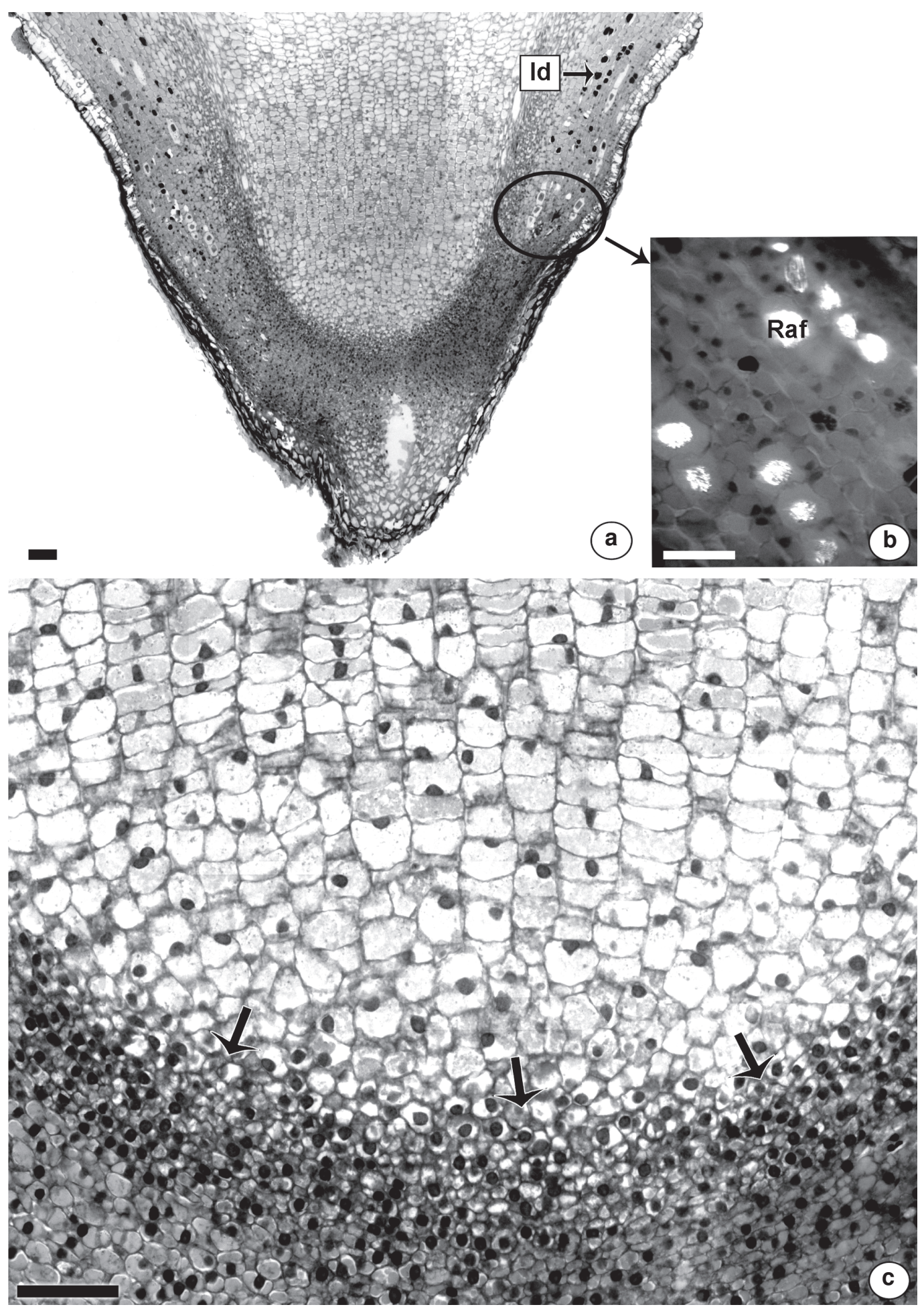

Figura 5 - Raiz adventícia de Smilax subsessiliflora. Secções longitudinais - a. aspecto geral da porção apical; b. detalhe da porção cortical evidenciando idioblastos de ráfides (em MP); c. detalhe da porção apical evidenciando a região das células iniciais (setas). Id = idioblasto fenólico; Raf = ráfides. Escalas: $100 \mu \mathrm{m}$ (a-b); $25 \mu \mathrm{m}$ (c).

Figure 5 - Adventitious root of Smilax subsessiliflora. Longitudinal sections - a. general view of apical portion; b. detail of cortical portion showing raphid idioblasts (in MP); c. detail of apical portion showing region of initial cells (arrows). Id = phenolic idioblasts; Raf $=$ raphids. Scales: $100 \mu \mathrm{m}(\mathrm{a}-\mathrm{b}) ; 25 \mu \mathrm{m}(\mathrm{c})$. 


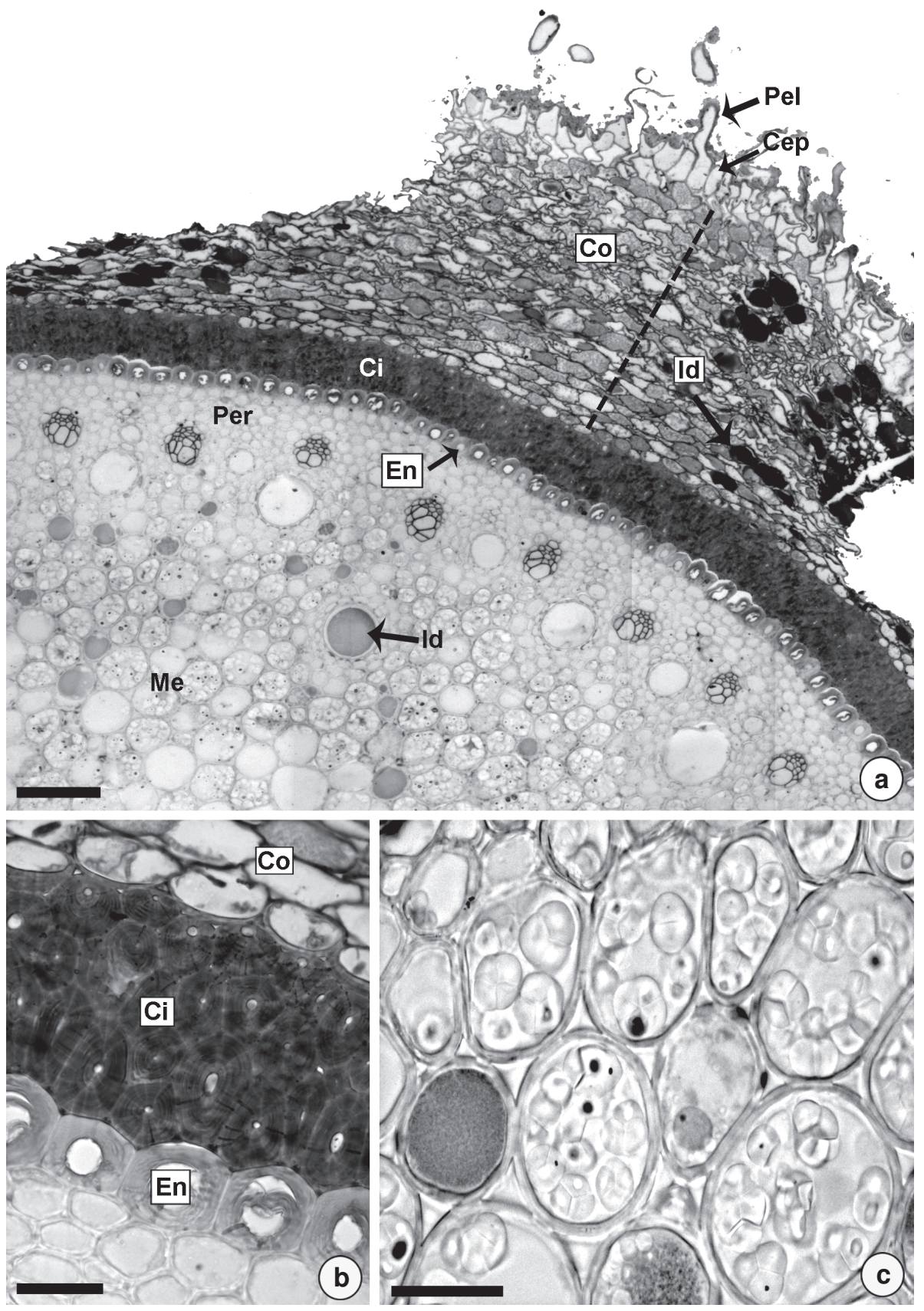

Figura 6 - Raiz adventícia de Smilax subsessiliflora. Secção transversal - a. resquícios do córtex, onde se observam células epidérmicas, pêlos radiculares e córtex externo; córtex interno com esclereides, endoderme com espessamento em "O"; bem como periciclo em várias camadas celulares, xilema e floema alternados, e medula; b. detalhe da figura anterior, evidenciando o córtex interno e a endoderme; c. células da medula contendo grãos de amido. Pel = pêlo radicular; $\mathrm{Cep}=$ célula epidérmica; $\mathrm{Co}=$ córtex, porção externa; $\mathrm{Ci}=$ córtex, porção interna; $\mathrm{En}=$ endoderme; Per = periciclo; Id = idioblasto fenólico; $\mathrm{Me}=$ medula. Escalas: $100 \mu \mathrm{m}$ (a); $25 \mu \mathrm{m}$ (b); $50 \mu \mathrm{m}$ (c).

Figure 6 - Adventitious root of Smilax subsessiliflora. Transversal section - a. remains of the cortex, with epidermal cells, root hairs and outer cortex; inner cortex with sclereids, endodermis with "O" thickening. Besides the pericycle in several cell layers; alternated xylem and phloem, and pith; b. detail of the previous figure, showing inner cortex and thick-walled endodermis; c. pith cell with starch grains. $\mathrm{Pel}=$ root hair; $\mathrm{Cep}=$ epidermal cell; $\mathrm{Co}=$ outer cortex; $\mathrm{Ci}=$ inner cortex; $\mathrm{En}=$ endodermis; $\mathrm{Per}=$ pericycle; $\mathrm{Id}=$ phenolic idioblast; $\mathrm{Me}=$ pith. Scales: $100 \mu \mathrm{m}$ (a); $25 \mu \mathrm{m}$ (b); $50 \mu \mathrm{m}$ (c). 
A cerca de 1,7 mm do ápice da raiz lateral tem início a zona pilífera com pêlos radiculares de paredes espessadas (Fig. 7a). Idioblastos fenólicos e outros portadores de ráfides são observados em todo o córtex.

A região mais externa do córtex é constituída por quatro camadas de células parenquimáticas, onde ocorrem endomicorrizas arbusculares (Fig. 7b). Mais internamente, observa-se uma camada de esclereides cujas paredes anticlinais, assim como as periclinais internas são espessadas e pontoadas (Fig. 7c). O estrato mais interno do córtex é representado pela endoderme que é constituída por células com paredes irregularmente espessadas. Esse espessamento pode se manifestar em todas as paredes da célula ou apenas nas anticlinais e nas periclinais externas (Fig. 7c). As células de passagem, localizadas nas proximidades dos elementos de protoxilema, são desprovidas de espessamento.

O cilindro vascular desta raiz é diarco e protostélico, e o periciclo é constituído por uma camada de células parenquimáticas com paredes delgadas (Fig. 7c).

\section{Discussão}

O caule subterrâneo das espécies de Smilax tem sido designado na literatura especializada ora como rizóforo (Cunha 1937; Oliveira et al. 1973; Guaglianone \& Gattuso 1991; Palhares \& Silveira 2005; Silva 2006), ora como rizoma (Andreata \& Menezes 1999; Martins \& Appezzato-da-Glória 2006), com base, principalmente, nos aspectos morfológicos. Menezes et al. (1979), Sajo \& Menezes (1986), Rocha \& Menezes (1997) e Andreata \& Menezes (1999), analisando estruturas subterrâneas similares aos rizomas, que se distinguiam destes por apresentarem sistema bipolar de ramificação caulinar, adotaram uma nova interpretação para tais estruturas. Andreata \& Menezes (1999), acompanhando a ontogenia de Smilax quinquenervia, verificaram que o sistema subterrâneo desta espécie apresenta características de rizóforo, adotando assim este termo para desginá-la. Martins \& Appezzato-da-Gloria (2006), por sua vez, ao descreverem o sistema subterrâneo de Smilax polyantha Griseb. corroboraram a interpretação de Andreata \& Menezes (1999), e estenderam também o termo rizóforo para esta espécie. Fundamentada nesses estudos, Appezzato-da-Glória (2003) aponta critérios para distinguir rizoma e rizóforo. Segundo a autora, o rizoma tem origem na plúmula, enquanto o rizóforo se origina a partir de gemas cotiledonares ou pelo espessamento do hipocótilo.
No presente trabalho, embora não tenham sido desenvolvidos estudos ontogenéticos, optou-se pelo termo rizóforo para designar o sistema subterrâneo de S. subsessiliflora, dadas as características anatômicas observadas no órgão adulto, que se assemelham às relatadas para o rizóforo de $S$. quinquenervia - um sistema de ramificação bipolar, constituído pelo caule subterrâneo, do qual partem os ramos caulinares aéreos e o sistema radicular adventício. No entanto, fazem-se necessários estudos morfoanatômicos e ontogenéticos para melhor esclarecimento do assunto.

Andreata (1997) comenta que o posicionamento do rizóforo em relação ao solo pode variar de acordo com a espécie, dependendo do ambiente em que as mesmas ocorrem, apresentando-se vertical em $S$. brasiliensis Spreng. e horizontal em $S$. quinquenervia. Nos espécimes de $S$. subsessiliflora aqui analisados, o rizóforo se posiciona horizontalmente.

Análises anatômicas evidenciaram a ocorrência de estômatos na epiderme do rizóforo de $S$. subsessiliflora, aspecto também mencionado por Andreata \& Menezes (1999) para S. quinquenervia e por Palhares \& Silveira (2005) para S. goyazana. Andreata \& Menezes (1999) e Appezzato-da-Glória (2003) consideraram que a presença de estômatos na epiderme de rizóforos pode evidenciar que estes órgãos derivam de um órgão ancestral aéreo.

Em S. subsessiliflora, na porção mediana do rizóforo, ocorre uma ampla região de meristema de espessamento primário (MEP), localizada ente o córtex e o cilindro vascular, responsável pelo aumento do órgão em espessura, assim como pela formação de novos elementos vasculares e das raízes adventícias. Esses resultados corroboram as observações de DeMason (1980), em que a autora considera que a zona situada entre o córtex e o cilindro vascular, o MEP, é responsável pelo aumento do caule em diâmetro. Rudall (1991) tem o mesmo pensamento e acrescenta que as conexões entre o sistema vascular do caule, da raiz e das folhas também se originam no MEP.

Andreata \& Menezes (1999), acompanhando o desenvolvimento do rizóforo de S. quinquenervia, observaram uma região de MEP cujas características são semelhantes às citadas para o rizóforo de $S$. subsessiliflora, aqui analisada. Já Martins \& Appezzato-da-Glória (2006) argumentam que no rizóforo de $S$. polyantha a produção do córtex secundário (na direção centrífuga) e de feixes vasculares, assim como de parênquima, em direção centrípeta, é uma consequência da atividade de um meristema de espessamento secundário (MES). 


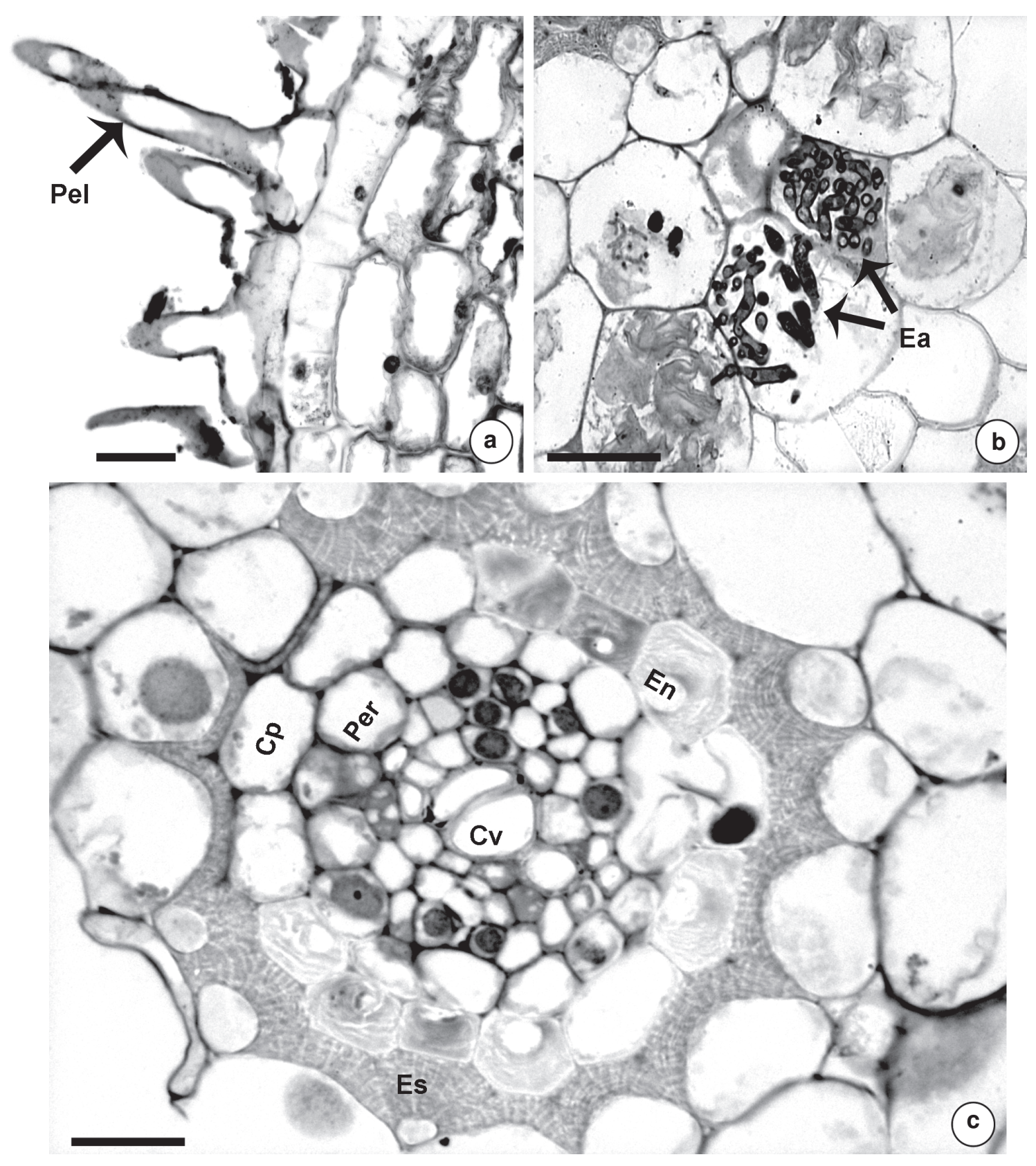

Figura 7 - Raiz lateral de Smilax subsessiliflora. Secção transversal - a. detalhe da epiderme e dos pêlos radiculares; b. detalhe da região cortical, evidenciando as endomicorrizas arbusculares; c. região central, evidenciando camada uniestratificada de esclereides, endoderme com células de passagem, e cilindro vascular protostélico. Ea = endomicorrizas arbusculares; $\mathrm{Pel}=$ pêlo radicular; $\mathrm{Es}=$ esclereides; $\mathrm{En}=$ endoderme $\mathrm{Cp}=$ célula de passagem; $\mathrm{Per}=$ periciclo; $\mathrm{Cv}=$ cilindro vascular. Escalas: $100 \mu \mathrm{m}(\mathrm{a}) ; 50 \mu \mathrm{m}(\mathrm{b}-\mathrm{c})$.

Figure 7 - Lateral root of Smilax subsessiliflora. Transversal section - a. detail of epidermis and root hairs; b. detail of cortex region, showing arbuscular endomycorrhizae; c. central region, showing unistratified layer of sclereids, with thick pitted walls, endodermis with passage cell and protostelic vascular cylinder. $\mathrm{Ea}=$ arbuscular endomycorrhizae; $\mathrm{Pel}=$ root hair; Es = sclereids; En = endodermis; $\mathrm{Cp}=$ passage cells; Per $=$ pericycle; $\mathrm{Cv}=$ vascular cylinder. Scales: $100 \mu \mathrm{m}(\mathrm{a}) ; 50 \mu \mathrm{m}(\mathrm{b}-\mathrm{c})$ 
De acordo com DeMason (1983), a distinção entre MEP e MES é muito tênue, e alguns autores divergem quanto à interpretação da extensão desses meristemas. Cheadle (1937) considera que o MES é análogo ao câmbio vascular das dicotiledôneas e das gimnospermas. DeMason (l.c.), ao contrário, chama a atenção para o fato de que os tipos secundários produzidos em ambos os meristemas são muito distintos e ressalta a necessidade de estudos mais acurados a respeito. Por outro lado, Menezes et al. (2005) discutem a atividade meristemática da endoderme e do periciclo no espessamento primário de monocotiledôneas.

Os resultados observados corroboram o pensamento de De Mason (1983) no que diz respeito à dificuldade em separar os limites entre MEP e MES, e em relação à diversidade dos tipos secundários produzidos por esses dois meristemas e ressalta-se também a necessidade de estudos mais acurados a respeito. Por outro lado, discorda-se de Cheadle (1937) quanto à analogia entre o MES e o câmbio vascular das dicotiledôneas e das gimnospermas. Outrossim, o que se refere ao reflexo da atividade meristemática da endoderme e do periciclo no processo de espessamento primário, referido por Menezes et al. (2005), não foi observado no material aqui analisado.

O cilindro vascular do rizofóro de $S$. subsessiliflora é integrado por feixes colaterais envoltos por bainha esclerenquimática, no que difere do que foi descrito por Palhares \& Silveira (2005) para o rizoma de $S$. goyazana A. DC., em que os autores relatam a presença de uma endoderme com estrias envolvendo cada feixe vascular. Martins \& Appezzato-da-Glória (2006) assinalam também a ocorrência de feixes vasculares envoltos por células com paredes espessadas e lignificadas que acumulam amido, no rizóforo de $S$. polyantha.

No rizóforo de $S$. subsessiliflora foi observada grande quantidade de metabólitos secundários, dispersos por todo o órgão, sendo a maioria representada por idioblastos fenólicos. Martins \& Appezzato-da-Glória (2006) constataram a presença de idioblastos fenólicos apenas no cilindro vascular do rizóforo de $S$. polyantha. A ocorrência de metabólitos secundários no gênero Smilax foi igualmente assinalada por Cunha (1937), Oliveira et al. (1973), Andreata (1980), Guaglianone \& Gattuso (1991), Rugna et al. (2003), Palhares \& Silveira (2005), Martins \& Appezzato-da-Glória (2006), e Silva (2006). Dentre estes metabólitos secundários, as saponinas são consideradas como as principais responsáveis pela atividade farmacológica do gênero Smilax (Rugna et al. 2003). Segundo os autores a predominância de cumarinas, flavonóides e esteróides (saponinas) no rizoma de S. campestris é um dado importante, que pode servir como marcador quimiotaxonômico para a espécie.

Nas raízes de maior calibre a substituição do córtex externo pela porção interna, que passa a exercer a função de revestimento, foi também mencionada por Martins \& Appezzato-da-Glória (2006) em S. polyantha. Oliveira et al. (1973) relatam igualmente a ocorrência de esclereídes no córtex interno da raiz de $S$. japecanga, comentando que nem sempre essas células estão presentes. A endoderme de $S$. subsessiliflora apresenta células de paredes com espessamento em "O", semelhante ao relatado para a raiz de $S$. polyantha (Martins \& Appezzato-da-Glória 2006) e para outras espécies brasileiras do gênero Smilax (Cunha 1940). Esau (1974) também relatou este tipo de espessamento para S. herbacea L. e Eames \& MacDaniels (1947), para $S$. rotundifolia L.

Em S. subsessiliflora o cilindro vascular da raiz adventícia é poliarco e sifonostélico, à semelhança do que foi descrito para $S$. polyantha (Martins \& Appezzato-da-Glória 2006). O periciclo de $S$. subsessiliflora é formado por 3-4 estratos de células com paredes ligeiramente espessadas e a região medular, conspícua, difere da raiz de $S$. japeganga em que esta região é pouco desenvolvida (Oliveira et al. 1973).

Smilax subsessiliflora apresenta grande proporção de grãos de amido compostos no periciclo e na região medular. Já em $S$. polyantha o amido está presente apenas na medula radicular (Martins \& Appezzato-da-Glória 2006). A ocorrência de amido nos órgãos subterrâneos indica que os mesmos exercem a função de armazenamento, e pode estar relacionada com a sobrevivência do vegetal em condições adversas (Kolb et al. 1998).

Nas células corticais das raízes laterais em $S$. subessiliflora constatou-se a presença de endomicorrizas arbusculares. Segundo Akiyama et al. (2005), a maioria das plantas vive em simbiose com fungos ou em associações com bactérias que otimizam sua nutrição. Fungos endomicorrízicos arbusculares (FMA) estabelecem associações simbióticas com as raízes em mais de $80 \%$ das plantas terrestres. Pouco se sabe, porém, sobre os mecanismos moleculares que regulam essas associações, assim como a respeito do reconhecimento entre fungos e plantas hospedeiras (Akiyama et al. 2005). Após a entrada das endomicorrizas arbusculares numa 
célula epidérmica, o fungo se desenvolve e coloniza o meio intercelular das células corticais, sem penetrar na endoderme (Reinhardt 2007). Tal situação foi também observada na espécie em estudo.

O cilindro vascular da raiz lateral em $S$. subsessiliflora é diarco e protostélico, no que difere da raiz de primeira ordem. Diferenças também ocorrem com relação à endoderme, em que algumas células apresentam espessamento nas paredes periclinais externas e nas anticlinais. Acredita-se que a raiz adventícia, portadora de grande proporção de grãos de amido, desempenharia, preferencialmente, a função de armazenamento. Já a raiz lateral, por suas características estruturais e pela associação com endomicorrízas arbusculares, teria como função principal a absorção de água e de nutrientes.

Espera-se com este estudo contribuir para estudos futuros, como a análise ontogenética do rizóforo, a fim de acompanhar seu desenvolvimento e verificar se o meristema responsável pelo espessamento do órgão é de origem primária ou secundária; e futuras pesquisas fitoquímicas, a partir das análises histoquímicas realizadas, como registro de idioblastos fenólicos e amilíferos no rizóforo, revelando o potencial químico do órgão.

\section{Agradecimentos}

À Agência de fomento CAPES, a concessão da bolsa de mestrado à primeira autora e ao $\mathrm{CNPq}$ as bolsas de Produtividade em Pesquisa das demais autoras e o auxílio financeiro outorgado a Regina Potsch Andreata (Proc. 473850/2006-0). Ao Instituto de Pesquisas Jardim Botânico do Rio de Janeiro, a franquia dos seus laboratórios, e a ajuda dos técnicos. Ao MSc. Gabriel U. Cruz Araújo pela tradução do resumo e das legendas para a língua inglesa.

\section{Referências}

Akiyama, K.; Matsuzaki, K. \& Hayashi, H. 2005. Plant sesquiterpenes induce hyphal branching in arbuscular mycorrhizal fungi. Nature 435: 824-827.

Andreata, R.H.P. 2009. A new species of Smilax and a key to all species from Minas Gerais, Brazil. Systematic Botany 34: 28-31.

Andreata, R.H.P. 1980. Smilax Linnaeus (Smilacaceae). Ensaio para uma revisão taxonômica das espécies brasileiras. Arquivos do Jardim Botânico do Rio de Janeiro 24: 179-301.

Andreata, R.H.P. 1997. Revisão das espécies brasileiras do gênero Smilax Linnaeus (Smilacaceae). Pesquisas - Botânica 47: 7-244.

Andreata, R.H.P. \& Menezes, N.L. 1999. Morfoanatomia do embrião, desenvolvimento pós-seminal e origem do rizóforo de Smilax quinquenervia Vell. Boletim de Botânica da Universidade de São Paulo 18: 39-51.

Appezzato-da-Glória, B. 2003. Morfologia de sistemas subterrâneos: histórico e evolução dos conhecimentos no Brasil. A.S. Pinto, Ribeirão Preto. 80p.

Berlyn, G.P. \& J.P. Miksche. 1976. Botanical microtechnique and cytochemistry. The Iowa State University Press, Ames. 336p.

Bukatsch, F. 1972. Bermerkungen zur Doppelfarbung Astrablau-Safranin. Mikrokosmos 61: 255.

Cheadle, V.I. 1937. Secondary growth by means of a thickening ring in certain monocotyledons. Botanical Gazette 98: 535-555.

Considine, J.A. \& Knox, R.B. 1979. Development and histochemistry of the cells, cell walls, and cuticle of the dermal system of fruit of the grape, Vitis vinifera L. Protoplasma 99: 347-365.

Cunha, N.S. 1937. Da salsaparrilha a japecanga. Tribuna Farmacêutica 5: 145-150.

Cunha, N.S. 1940. As salsaparrilhas em face da farmacopéia brasileira. Tribuna Farmacêutica 8:105-112.

Demason, D.A. 1980. Localization of cell division activity in the primary thickening meristem in Allium cepa L. American Journal of Botany 67: 393-399.

Demason, D.A. 1983. The primary thickening meristem: definition and function in monocotyledons. American Journal of Botany 70: 955-962.

Eames, A.J. \& MacDaniels, L.H. 1947. Introduction to plant anatomy. 2 ed. Book Company Inc., New York. 427p.

Esau, K. 1974. Anatomia das plantas com sementes. Edgard Blucher, São Paulo. 293p.

Gerrits, P.O. \& Smitd, L. 1983. A new, less toxic polymerization system for the embedding soft tissues in glycol methacrilate and subsequent preparing of serial sections. Journal of Microscopy 132:81-85.

Guaglianone, R. \& Gattuso, S. 1991. Estúdios taxonômicos sobre el gênero Smilax (Smilacaceae). Boletin de la Sociedade Argentina de Botânica, 27: 105-129.

Hongzhu, G.; Koike, K.LW.; Guo, D. \& Nikaido, T. 2004. Maltol glucosides from the tuber of Smilax bockii. Phytochemistry 65: 481-484.

Jensen, W.A. 1962. Botanical histochemistry: principle and practice. W. H. Freeman, San Francisco. 408p.

Johansen, D.A. 1940. Plant microtechnique. McGrawHill Book Company Inc., New York. 523p.

Kolb, R.M.; Medri, M.E.; Bianchini, E.; Pimenta, J.A.; Giloni, P.C. \& Correa, G.T. 1998. Anatomia ecológica de Sebastiania commersoniana (Baillon) Smith \& Downs (Euphorbiaceae) submetida ao alagamento. Revista Brasileira de Botânica 21: 305-312.

Lei da Anvisa - Resolução RDC n 48. 2004. Diário Oficial da União - Poder Executivo.

Martins, A.R. \& Appezzato-Da-Glória, B. 2006. Morfoanatomia de órgãos vegetativos de Smilax polyantha Griseb. (Smilacaceae). Revista Brasileira de Botânica 29: 555-567. 
Medeiros, M.F.T.; Senna-Vale, L. \& Andreata, R.H.P. 2007. Histórico e o uso da "salsa parrilha" (Smilax spp.) pelos boticários no Mosteiro de São Bento. Revista Brasileira de Biociências 5: 27-29.

Menezes, N.L.; Muller, C. \& Sajo, M.G. 1979. Um novo e peculiar tipo de sistema subterrâneo em espécies de Vernonia da Serra do Cipó (Minais Gerais, Brasil). Boletim de Botânica 7: 33-38.

Menezes, N.L.; Silva, D.C.; Arruda, R.C.O.; Melo-De-Pina, G.F.; Cardoso, V.A.; Castro, N.M.; Scatena, V.L. \& Scremin-Dias, E. 2005. Meristematic activity of the endodermis and the pericycle in the primary thickening in monocotyledons. Considerations on the PTM. Anais da Academia Brasileira de Ciências 77: 259-274.

Oliveira, F.; Silva, J.B. \& Rocha, A.B. 1973. Contribuição para o reconhecimento do rizoma de Smilax japecanga Grisebach. Revista da Faculdade de Farmácia e Odontologia de Araraquara 7: 7-18.

Palhares, D. \& Silveira, C.E.S. 2005. Estudo anatômico do rizoma de Smilax goyazana A. DC. (Smilacaceae). Revista Brasileira de Plantas Medicinais 8: 52-62.

Peckolt, O. 1936. Sobre a planta produtora da japenga. Revista Flora Medicinal 2: 513-517.

Pharmacopéia dos Estados Unidos do Brasil. 1929. 1 ed. São Paulo, Ed. Nacional. 1149p.
Reinhardt, D. 2007. Programming good relations development of the arbuscular mycorrhizal symbiosis. Plant. Biology 10: 98-105.

Rocha, D.C. \& Menezes, N.L. 1997. O sistema subterrâneo de Dioscorea kunthiana Uline ex R. Knuth (Dioscoriaceae). Boletim de Botânica Universidade de São Paulo 16: 113.

Rudall, P. 1991. Lateral meristems and stem thickening growth in monocotyledons. The Botanical Review 57: $150-163$.

Rugna, Z.A.; Vugin, A.; Gurni, A. \& Wagner, L.M. 2003. Marcha fitoquímica comparativa entre las hojas y los rizomas de Smilax campestris Griseb. Smilacaceae. Dominguezia 19: 25-29.

Rugna, Z.A.; Gurni, A.A. \& Wagner, L.M. 2005. Fitoquímica comparativa de flavonoides en los diferentes órganos de Smilax campestris Griseb. Smilacaceae. Dominguezia 21: 17-23.

Sajo, M.G. \& Menezes, N.L. 1986. Origem e crescimento do rizóforo em espécies de Vernonia Screb. (Compositae) da Serra do Cipó, MG. Revista Brasileira de Biologia 46: 197-202.

Sakai, W.S. 1973. Simple method for differential staining of paraffin embedded plant material using toluidine blue. Stain Technology 48: 247-248.

Silva, A.A.J. 2006. Plantas bioativas. Essentia herba 2: 408-423. 